\title{
Resistência e diversidade: narrativas culturais de uma comunidade quilombola
}

\author{
Valdir Pierote Silva \\ Universidade de São Paulo - USP, São Paulo, São Paulo, SP, Brasil. \\ Casa das Áfricas Amanar, São Paulo, SP, Brasil.
}

\begin{abstract}
Resumo: Riacho das Pedras era uma comunidade remanescente de quilombo localizada no município de Rio de Contas (Bahia), cujas terras foram inundadas após a construção de uma barragem. A obra gerou graves impactos para a população atingida e também para o meio ambiente do entorno. Entre os anos de 2008 e 2009, realizamos estudo de cinco trajetórias de ex-moradores desse vilarejo. A partir das narrativas, procuramos cartografar os processos de deslocamento, o estabelecimento nos novos territórios e as atuais condições daquele grupo. Para construção da pesquisa, utilizamos entrevistas, pesquisa bibliográfica, campo de inspiração etnográfica e técnicas do método história oral de vida. O objetivo deste artigo é fazer uma análise focando as manifestações culturais do quilombo e as repercussões dessas práticas no contexto local. Consideramos que, apesar da diáspora, a comunidade tem resistido politicamente e se afirmado por meio de manifestações artísticas e culturais. Compreendemos também que parte dos ex-moradores de Riacho das Pedras tem (re)criado formas de expressão específicas que os valorizam positivamente. Além disso, por meio dessas expressões, efetuam-se importantes variações culturais que contribuem para a ampliação da diversidade em Rio de Contas.
\end{abstract}

Palavras-chave: Narrativas, Comunidade Quilombola, Diversidade Cultural, Resistência.

\section{Resistance and diversity: cultural narratives of a quilombola community}

\begin{abstract}
Riacho das Pedras was a remnant quilombo community in the municipality of Rio de Contas (Bahia) which lands were flooded after the construction of a dam. The work led to serious impacts on the affected population and to the surrounding environment. We performed a five trajectories study of former residents of this village between 2008 and 2009. Based on the narratives, we sought to map the displacement processes, the establishment in new territories and the group current conditions. Our project was developed based on interviews, literature, ethnographic inspiration field and oral history of life method. This article aims to conduct an analysis focusing on the quilombo cultural manifestations and consequences of these practices in the local context. We believe that despite the diaspora, the community has endured and asserted itself politically through artistic and cultural events. We understand that the quilombo descendants have (re)created specific forms of expression that value them positively. Besides, through these expressions, important cultural variations are accomplished in order to contribute to the expansion of diversity in Rio de Contas.
\end{abstract}

Keywords: Narratives, “Quilombo” Community, Cultural Diversity, Resistance. 


\section{Introdução}

A proposta deste artigo nasceu do convite para contribuir com os encontros "Terapia Ocupacional e Cultura: Contextos e Possibilidades", que compreenderam parte dos estudos de pós-doutoramento da Profa. Dra. Patrícia Dornelles no Programa de Pós-Graduação em Terapia Ocupacional da Universidade Federal de São Carlos (PPGTO/UFSCar). Os encontros ocorreram no segundo semestre de 2014 e buscaram promover espaços de divulgação para trabalhos de terapeutas ocupacionais na interface com o campo cultural, e também procuraram levantar avanços, demandas e necessidades formativas.

A partir desse convite, uma importante questão se apresentou: por meio de qual ângulo poderíamos abordar a complexidade do tema proposto em uma apresentação oral e, depois, em um texto escrito? Os caminhos pareciam muitos, porém sempre intrincados e difíceis. Sobre o que falar e como escrever? Essas perguntas levaram-nos à compreensão deleuziana de que

[...] só escrevemos na extremidade de nosso próprio saber, nesta ponta extrema que separa nosso saber e nossa ignorância e que transforma um no outro (DELEUZE, 1988, p. 18).

Partindo então dessa perspectiva, surgiu a ideia de retomar nossa pesquisa sobre narrativas de uma comunidade quilombola na cidade de Rio de Contas (Bahia) realizada entre 2008 e 2009 (PIEROTE-SILVA, 2009).

Voltamos àquele trabalho em busca de pistas que pudessem nos ajudar a construir um percurso, mesmo que parcelar e transitório. Foi assim que organizamos a apresentaçáo oral e, agora, o presente artigo, cujo objetivo é realizar uma leitura da trajetória da comunidade quilombola de Riacho das Pedras com foco nas suas manifestaçóes culturais e nas repercussóes dessas práticas no contexto local.

\section{Histórias submersas:}

\section{construção e percurso da pesquisa}

No Brasil, são recorrentes violaçóes de direitos fundamentais como moradia e acesso à terra. Essa questão foi central na história de 30 famílias de Riacho das Pedras, um vilarejo remanescente de quilombo localizado no município de Rio de Contas (Bahia), cujos habitantes foram obrigados a se deslocar por terem suas terras inundadas após a construção da barragem Luiz Vieira. A obra, concluída em 1983, foi executada pelo Departamento Nacional de Obras
Contra as Secas (DNOCS) e gerou graves impactos para a população atingida e também para o meio ambiente do entorno. A pesquisa, baseada no estudo de cinco trajetórias ${ }^{1}$ de ex-moradores da antiga comunidade (um homem e quatro mulheres), procurou cartografar os processos de deslocamento, o estabelecimento nos novos territórios e as atuais condiçóes daquele grupo.

$\mathrm{O}$ interesse pelo estudo teve origem tanto na experiência particular, porque nossa família é da região e moramos em Rio de Contas por 17 anos, como também pelo desejo em discutir os impactos $\mathrm{da}$ construção da barragem na vida das pessoas afetadas. Assim, como método, utilizamos entrevistas, pesquisa bibliográfica, campo de inspiração etnográfica e técnicas do método história oral de vida (MEIHY, 2005; MEIHY; HOLANDA, 2007), além de termos algumas perguntas-chaves que nos guiaram: Como havia ocorrido o deslocamento da populaçáo obrigada a deixar suas casas e a repercussão desse movimento na vida das pessoas e da comunidade? Para onde foram? Como se reorganizaram? Como vivem nos dias de hoje e como narram os eventos vividos coletivamente? Qual a importância atribuída à questão racial nesses processos de deslocamento e nas trajetórias de vida? Buscou-se entender de que maneira tal mudança ocorreu na vida desses sujeitos, forçados a sair da terra natal, onde trabalharam, cultivaram relaçóes afetivas e simbólicas e desenvolveram formas singulares de sociabilidade.

\section{A diáspora de Riacho das Pedras: narrativas do deslocamento}

O relacionamento do Estado com os moradores de Riacho das Pedras durante o processo de construção da barragem Luiz Vieira foi marcado pelo autoritarismo e pela ausência de participação ou consulta aos que ali viviam. Àquela época, final da Ditadura Militar brasileira, era ainda mais grave a inobservância de mecanismos de prestaçáo de contas ou monitoramento do governo pela sociedade. As decisōes eram tomadas verticalmente e contavam com apoio de agentes repressivos em caso de alguma forma de resistência.

Um morador do quilombo, em entrevista concedida a Rocha (2002, p. 110), avaliou que a chegada do DNOCS gerou insatisfação e

[...] trouxe um grande transtorno pro pessoal, uma grande desilusão. Acreditava-se no governo e o governo foi o primeiro a liquidar o povo, a liquidar um povo sem satisfação nenhuma, a única satisfaçâo que algumas pessoas diziam era: vocês têm que sair, senão, vocês vão virar comida de peixe. 
Na mesma linha, um dos interlocutores da nossa pesquisa relembrou o processo:

Então chegou a barragem e já chegou logo atacando tudo. Quando eles chegaram a turma ficou quase sem saber pra onde ia. [...] O DNOCS chegou em Riacho das Pedras abrindo picada e falando que iria vir uma barragem e que todo mundo teria que sair do lugar (LOPES, 2009, p. 54) 2 .

Assomam-se ainda outros importantes fatos. No referido período, não existia regulamentação sobre terras de remanescentes de quilombo e muitos moradores não possuíam documentação das suas propriedades, e por essa razão foram desalojados sem ressarcimento. Em relatório de 1999, o próprio DNOCS reconheceu que 56 moradores, donos de 355,84 hectares terras, "[...] ficaram sem ser indenizados devido à inexistência da documentação de propriedade" (DEPARTAMENTO..., 1999, p. 5). Pessoas entrevistadas nas pesquisas de Vasconcelos e Souza Filho (2001), Rocha (2002) e Santos (2005) afirmaram ainda que os funcionários do órgão estatal extraviaram os comprovantes de posse de algumas pessoas que já tinham suas terras documentadas. Uma das nossas interlocutoras apontou o furto de seus papéis:

[...] o meu registro [da terra], os da minha irmã, o da minha mãe, eles [funcionários do DNOCS] tomaram falando que era pra levar pra poder fazer a indenização e, até hoje, estamos sem esses documentos. Sumiram todos os papéis, sumiram todinhos (AGUIAR, 2009, p. 83).

Em relato transmitido a Rocha (2002), o líder comunitário do quilombo concluiu que a construção da barragem

[...] trouxe muitas dores, muitas lágrimas, porque a empresa tomou todas as nossas terras, porque tomou todos os documentos atuantes que tinha no momento. A empresa fez o que bem quis (ROCHA, 2002, p. 108).

Segundo Santos (1993, p. 61-62), o

[...] território em que vivemos é mais que um simples conjunto de objetos, mediante os quais trabalhamos, circulamos, moramos, mas é também um dado simbólico [...] [Assim] a territorialidade [...] náo provém do simples fato de viver num lugar, mas da comunhão que com ele mantemos.

Esta relação de comunhão cria marcas nas pessoas e no espaço onde vivem e, nesse sentido, o deslocamento dos moradores de Riacho das Pedras significou não apenas a perda física das terras ancestrais, mas também a expropriação da geografia de um universo simbólico e cultural.

De acordo com as narrativas dos nossos interlocutores, incertezas, injustiças, desestabilidade, falta de apoio e sofrimentos foram as marcas do processo de deslocamento da comunidade natal. Durante a diáspora do povoado, a maior parte dos habitantes migrou para outra área rural da cidade chamada Barro Branco, distante aproximadamente $20 \mathrm{~km}$ das terras de origem. Contudo, essa nova povoação se extinguiu após cerca de 15 anos do estabelecimento dos deslocados. O riacho que servia Barro Branco secou e as pessoas não tinham como permanecer no local. Assim, na segunda metade da década de 1990, os ex-moradores de Riacho das Pedras mudaram-se novamente. Dessa vez, em sua grande maioria, o grupo fixou-se em uma região periférica da sede do município de Rio de Contas: área pobre, estigmatizada e habitada majoritariamente por negros descendentes das comunidades quilombolas ${ }^{3}$. Trata-se do bairro conhecido como Pirulito, cuja escolha como porto teve importante influência da prefeitura, que distribuiu lotes devolutos para alguns dos egressos de Barro Branco e de Riacho das Pedras.

Além disso, os ex-moradores que não receberam a doação do município compraram terrenos no mesmo espaço devido ao preço mais baixo e também pela proximidade que teriam de amigos e parentes. Desse modo, Pirulito foi constituindo-se como o bairro negro e periférico de Rio de Contas.

Há poucas décadas, a apartação racial era também institucionalizada no estatuto do clube social da cidade, que proibia a entrada de negros nos seus eventos. Uma das interlocutoras da pesquisa vivenciou essa época:

[...] aqui em Rio de Contas eu já sofri discriminação. Eu estava na sétima série, em 1981, e fui numa festa no clube e o porteiro me barrou por que eu sou negra. Tinha o clube dos brancos e a associação pros negros. O porteiro falou: "aqui não, seu lugar é ali na frente”, que era a associaçáo. Eu estava morando aqui em Rio de Contas, estava estudando (SILVA, 2009, p. 65).

Mesmo se tratando de uma cidade pequena, cuja população da sede municipal não passa de $5 \mathrm{mil}$ habitantes, criou-se um arranjo urbanístico que estabeleceu um centro e uma periferia que distam apenas $500 \mathrm{~m}$. Um centro tombado pelo patrimônio histórico nacional, habitado quase exclusivamente por brancos, com grandes casaróes de antigos coronéis 
e praças bem cuidadas. E, por outro lado, uma periferia negra e pobre, sem pavimentação, fora do perímetro do tombamento e com casas modestas.

Além disso, no período no qual vivíamos na cidade, não se ouvia falar da inundação de Riacho das Pedras nas escolas, nas aulas de história local. Havia, no máximo, a citação da existência das comunidades quilombolas no município como um dado exótico e/ou turístico. Diferentemente, narrativas coloniais sobre os bandeirantes e garimpeiros que fundaram Rio de Contas eram valorizadas e difundidas - inclusive com uma homenagem em forma de escultura na Praça Matriz (PIEROTE-SILVA, 2014). Desse modo, assim como a periferia negra parece não caber na organização urbana oficial e patrimonializada, a trajetória da comunidade Riacho das Pedras e o processo de deslocamento dos seus moradores parecem não fazer parte da história hegemônica da cidade.

Trata-se, no fundo, de um sistemático apagamento das histórias do povo negro que se inicia no período escravocrata - quando famílias eram brutalmente separadas e nomes próprios trocados ou aportuguesados - e que se expressa nos séculos seguintes na falta de interesse em se registrar as trajetórias dessa populaçáo desde seu ponto de vista. No caso da comunidade quilombola de Riacho das Pedras, há ainda o agravante da destruição do seu território físico, extremamente simbólico como marca da resistência negra na região. $\mathrm{O}$ antigo vilarejo foi totalmente inundado e náo houve nenhuma preocupação do Estado em conservar as memórias que estavam grafadas naquela geografia. Como ensina Benjamin (1993, p. 225), é necessário "escovar a história a contrapelo" para conseguir perceber trajetórias intencionalmente esquecidas ou sistematicamente apagadas.

Anular narrativas minoritárias - como o caso de Riacho das Pedras - é fundamental para a manutenção de historiografias coloniais cuja função é, a todo custo, sustentar a ordem social estabelecida e suas desigualdades correlatas. Em Rio de Contas, por exemplo, quase ninguém conhece o doloroso e injusto processo de deslocamento forçado a que os moradores da comunidade quilombola foram submetidos. Nessa perspectiva, histórias subterrâneas necessitam vir à tona para criar mutações nas forças estabelecidas e produzir novos arranjos políticos, sociais e econômicos (PIEROTE-SILVA; BARROS, 2010).

Nos últimos anos, contudo, a população negra do município tem conseguido imprimir marcas na narrativa da cidade por meio da participaçáo política - impulsionada pelo reconhecimento das comunidades quilombolas locais em 1999 - e pela afirmação das suas manifestações culturais singulares. Essas novas forças têm provocado ruídos e fissuras que, pouco a pouco, podem questionar o discurso hegemônico alicerçado em figuras violentas e autoritárias - como bandeirantes e coronéis - que vêm sendo oficialmente traduzidas como responsáveis pelo "progresso" e "desenvolvimento" da região.

\section{Resistência e diversidade: manifestações culturais quilombolas}

Como já apontado, antes do alagamento Riacho das Pedras formava uma unidade populacional em conjunto com duas outras comunidades: Barra e Bananal. Os três vilarejos apresentavam história e imaginário comuns, além de uma rede de sociabilidade conectada (PIEROTE-SILVA, 2009; MESSEDER; MARTINS, 1991). Contudo, após a inundação e diáspora dos moradores de Riacho das Pedras, outras dinâmicas se estabeleceram, mas ainda é possível afirmar que existem expressōes culturais específicas da unidade quilombola de Rio de Contas.

A partir de referências dos interlocutores da nossa pesquisa (PIEROTE-SILVA, 2009), de revisão bibliográfica (PINHEIRO; COSTA, 200-?; MESSEDER; MARTINS, 1991; MIRANDA, 1992; MESQUITA, 2000; SAKAMOTO, 2000; CAPINAN, 2009; CARDOSO, 2014; PIEROTE-SILVA, 2014) e do Relatório de Identificação da Comunidade de Barra, Bananal e Riacho das Pedras (MESSEDER, 1998), foi possível cartografar três manifestaçôes culturais distintivas:

Terno de Reis do Barro Branco: formado por 25 membros em média, compreende em sua maioria pessoas que foram deslocadas de Riacho das Pedras e que também viveram no povoado de Barro Branco. Trata-se de um cortejo de músicos entre as casas da cidade representando a história bíblica dos Reis Magos. O grupo existe há várias décadas - embora tenha mudado de nome e de integrantes ao longo do tempo - e já se apresentava no território original antes do deslocamento. No início, o Terno era realizado durante os meses de dezembro, janeiro e fevereiro, período que representa os primeiros meses de vida de Jesus Cristo.

Encomendaçáo das Almas: rito realizado para pedir progresso espiritual aos mortos no período da quaresma. Durante a noite, vestidos com grandes lençóis brancos e segurando velas acesas, os integrantes realizam longas oraçóes para aliviar as penas das almas pecadoras.

Bendengó (ou bendegó): espécie de brincadeira de roda com batida de palmas compassadas e sobre a qual não há referências em nenhuma outra 
região da Bahia (PINHEIRO; COSTA, 200-?). Dança bastante próxima ao "bendengué", um tipo de jongo da Costa de Mina ${ }^{4}$ descrito por Câmara Cascudo (1988) no Dicionário do Folclore Brasileiro.

Essas três formas de expressão têm vivido intensas dinâmicas nos últimos anos, compreendendo assimilações, transformações, invenções criativas, intercâmbios e negociaçôes. O Terno de Reis do Barro Branco, por exemplo, tem alterado as datas das suas apresentaçóes, deixando de respeitar o calendário religioso, para realizar turnês em outras cidades em eventos culturais. O ritual da Encomendação das Almas, por sua vez, havia quase desaparecido (MESQUITA, 2000) e, atualmente, tem sido retomado como performance e realizado em teatros e espaços culturais por alguns membros da comunidade quilombola. $\mathrm{O}$ mesmo tem ocorrido com o Bendengó, que se transformou de uma brincadeira cotidiana quase em desuso em performance artística apresentada em espetáculos de cultura na cidade e em outras regiốes, como Salvador. A partir de 1999, ano de reconhecimento das terras como remanescente de quilombo, iniciou-se também a associação e identificação das manifestaçôes culturais do grupo com a noção de quilombo.

Um dos interlocutores do nosso estudo era o coordenador do Terno de Reis de Barro Branco e que também dançava o Bendengó. Ele comentou:

Eu tenho 25 componentes que comando [no Terno de Reis]. Vamos até outras cidades. Esse ano que passou nós fomos a Várzea, a Barra, a Livramento. E ainda tem pra nós irmos: Mato Grosso, Marcolino Moura e Arapiranga. Existe também o bendengó, que eu participo. Fui até pra Salvador com o grupo e foi bom. Foi um encontro, onde nos dançamos. O lugar mais longe que o grupo esteve foi Salvador. Agora, o grupo já foi aqui em Boninal, mas eu não fui não. Atualmente, a gente só fica na regiáo. Apresentamos aqui na cidade quando teve a Domingueiras ${ }^{5}$ (LOPES, 2009, p. 61).

Parece que há pouco mais de duas décadas essas três expressões eram eventos e rituais íntimos dos povoados negros de Rio de Contas e não existia a difusão cultural vivenciada hoje, tampouco havia a associação dessas expressões à categoria política de quilombo. A identificação quilombola ganhou força a partir do reconhecimento do grupo pelo Estado em 1999, o que gerou inúmeras transformaçóes, mobilizaçôes, acesso a direitos e possibilidades, além do trânsito em novos circuitos de produção de valor.

Há, portanto, uma importante mudança: cada vez mais, os negros de Rio de Contas têm conseguido ocupar novos espaços por meio da participação política e de expressóes culturais. Pessoas que não podiam sequer rememorar as lutas de seus antepassados - uma vez que na cidade se evitava falar sobre ascendência africana, por se tratar de uma característica muito pejorativa no contexto local -, vêm agora rompendo ativamente essa lógica por meio de açóes políticas e criações artísticas e culturais.

Com efeito, parece que ao longo dos anos foi anulada a possibilidade de a população negra de Rio de Contas se afirmar como quilombola. Em nossa leitura, mecanismos discursivos e ideológicos de vexação e constrangimento atuavam para criar esquecimento em relação às lutas dos negros locais, caracterizando a condição de descendente de africanos como um aspecto indesejável, depreciativo e que não deveria ser enunciado. Por outro lado, observamos que transformaçóes provocadas pelas lutas do movimento social negro, pelo reconhecimento das terras remanescentes de quilombo e pelas açóes políticas associadas ao processo, efetuaram em Rio de Contas uma espécie de redevir quilombola ${ }^{6}$, ou seja, uma retomada da possibilidade de ser quilombola. $\mathrm{Na}$ verdade, o grupo negro do município nunca deixou de ser quilombola, mas essa identificação de resistência era extremamente combatida pela história dominante e pelas representaçóes hegemônicas. Trata-se de uma reconquista da diferença por meio da autovalorização criada com vários referenciais que transitam pela luta política associada à ideia de quilombo, pelas memórias ancestrais de resistência e até mesmo pelo catolicismo, pelos fluxos midiáticos e pela compreensáo de cultura como espetáculo. Em outros termos, o grupo tem criado antropofagicamente ${ }^{7}$ manifestaçóes singulares que vem transformando a si e as suas significaçóes na sociedade local.

A partir da potência da minoria, que se atualiza na possibilidade de catalisar mudanças no instituído, as narrativas e manifestaçóes dos quilombolas em Rio de Contas têm criado multiplicidades e mutaçóes nas representações dominantes. Para Deleuze (2010),

As minorias e as maiorias não se distinguem pelo número. Uma minoria pode ser mais numerosa que uma maioria. O que define a maioria é um modelo ao qual é preciso estar conforme: por exemplo, o europeu médio adulto macho habitante das cidades... ao passo que uma minoria não tem modelo, é um devir, um processo. [...] mas sua potência provém do que ela soube criar, e que passará mais ou menos para o modelo, sem dele depender (DELEUZE, 2010, p. 218).

Nessa perspectiva, com a positividade do que não subjugou outros discursos e nem pretende formatar a polifonia das narrativas em uma história única e 
linear, os quilombolas têm produzido novas relaçóes e têm trazido outras vozes e outras cores à paisagem social de Rio de Contas. Parece, portanto, que as expressóes culturais têm tido importante papel na afirmação do grupo, na produção do seu próprio reconhecimento como quilombola, nos seus processos de resistência e no forjamento da sua presença como ator coletivo na cidade.

Contudo, há um perigoso risco à espreita: a redução das lutas quilombolas a mero exotismo por meio da captura e textualização das manifestaçôes no discurso do folclore e do turismo mercadológico. Na pesquisa de Cardoso (2014), por exemplo, um descendente do quilombo descreveu as relaçôes entre as manifestaçôes da comunidade e o recém-criado Centro Cultural do Banco do Nordeste de Rio de Contas:

[...] religiosidade popular/encomendaçáo das almas ainda existe no quilombo, vai ser apresentado aqui no centro cultural do Banco do Nordeste dia 27 fevereiro, às 20:00 horas da noite a encomendação das almas, o Banco veio pra registrar todas essas culturas, é um projeto do Banco do Nordeste aqui em Rio de Contas... então o quilombo vai apresentar os reisados (CARDOSO, 2014, p. 100).

Em nossa análise, o desafio que se interpõe é conseguir transitar pelos diversos circuitos de produção de valor e manter, ao mesmo tempo, as expressóes abertas à variação, às multiplicidades e, portanto, resistindo à institucionalização, à reprodução do hegemônico e aos discursos unívocos. Assim, parece-nos pertinente pensar as manifestaçóes culturais como campos abertos com várias possibilidades de conexôes e entradas, inclusive acoplamentos parasitários e mortíferos. Em outras palavras, os movimentos gerados pela inventividade correm sempre o risco de serem cristalizados, classificados, convertidos em um grande "museu de cera" (WAGNER, 2014) e privados da sua força motriz - a vida.

\section{Multiplicar e denegrir ${ }^{8}$ a cultura}

Para Viveiros de Castro (2011), a "[...] vida vive da diferença: [e] toda vez que uma diferença se anula, há morte" (p. 8). Logo, falar em diversidade é referir-se à criação de novas formas de vida e a uma conexão ativa com a existência, uma vez que "existir é diferir" e "a diversidade, e não a unidade, está no coraçâo das coisas" (TARDE, 2007, p. 98, p. 104).

Nessa perspectiva, a diversidade pode ser traduzida também como um chamado para ação, para uma guerrilha simbólica contra mecanismos de fixação em formas hegemônicas e a favor de metamorfoses e invençôes criativas. Não se trata de "[...] celebrar ou lamentar uma diversidade passada, residualmente mantida ou irrecuperavelmente perdida" (VIVEIROS DE CASTRO, 2011, p. 9) e muito menos realizar estéreis catalogaçóes e inventários em supostos "resgates de culturas". Com efeito, consideramos que a resistência passa necessariamente pela criação de processos singulares que possam produzir

[...] uma cultura da afirmação, aberta a criação do novo, onde a vida, a ação e a liberdade voltem a ter mais importância que a conservação e a reprodução do instituído (PELLEJERO, 2008, p. 249).

Além disso, a emergência das manifestações quilombolas tem contribuído literalmente para denegrir a cultura local (NOGUERA, 2011, 2012), enriquecendo-a com cores negras. Rio de Contas torna-se mais escura, alegre e diversa, mesmo em um contexto histórico de etnocídio - isto é, de total apagamento das significaçôes de origem africana na regiấo. De modo potente, parte da populaçáo expulsa da comunidade de Riacho das Pedras tem se afirmado por meio de lutas e de inovaçóes inventivas, novas performances, sons, músicas, cantos e danças. Práticas e narrativas subterrâneas que têm produzido o húmus de uma cidade porvir.

\section{Referências}

AGUIAR, F. M. Uma história de sofrimento. [02 fev. 2009]. Entrevistador: Valdir Pierote Silva. Deslocamentos e histórias de vida: trajetória da comunidade quilombola Riacho das Pedras atingida pela construçāo da Barragem Luiz Vieira em Rio de Contas-BA. 2009. 170 f. Relatório (Iniciaçáo Científica) - Universidade de Sáo Paulo, Rio de Contas, 2009.

ANDRADE, O. A utopia antropofágica. São Paulo: Globo, 2011.

BENJAMIN, W. Obras escolhidas I: magia e técnica, arte e política. São Paulo: Brasiliense, 1993.

BOURDIEU, P. A ilusão biográfica. In: AMADO, J.; FERREIRA, M. M. (Coord.). Usos e abusos da história oral. Rio de Janeiro: FGV, 2000. p. 183-191.

CAPINAN, U. O quilombo que remanesce. Estudo de caso acerca dos impactos da política de certificação e de titulaçáo do território sobre a identidade étnica dos quilombos remanescentes Barra e Bananal em Rio de Contas, Bahia. 2009. 205 f. Dissertação (Mestrado em Ciências Sociais) - Universidade Federal da Bahia, Salvador, 2009.

CARDOSO, C. E. R. S. O processo de construção identitária da comunidade quilombola da Barra - Rio de Contasl Bahia. 2014. 136 f. Dissertaçáo (Mestrado em Letras: Cultura, Educação e Linguagens) - Universidade Estadual do Sudoeste da Bahia, Vitória da Conquista, 2014.

CASCUDO, L. C. Dicionário do folclore brasileiro. São Paulo: EDUSP, 1988. 
CASTRO, E. V. Desenvolvimento econômico e reenvolvimento cosmopolítico: da necessidade extensiva à suficiência intensiva. Sopro, Florianópolis, n. 51, p. 1-10, 2011.

DANOWSKI, D.; CASTRO, E. V. Há mundo por vir? Ensaio sobre os medos e os fins. Florianópolis: Instituto Socioambiental, 2014.

DELEUZE, G. Diferença e repetição. Rio de Janeiro: Graal, 1988

DELEUZE, G. Conversações. São Paulo: Editora 34, 2010 .

DEPARTAMENTO NACIONAL DE OBRAS CONTRAS AS SECAS - DNOCS. Comunidades negras de Barra, Bananal e Riacho das Pedras. Salvador, 1999. (Relatório mimeo).

LOPES, B. S. A história de Benedito. [25 jan. 2009]. Entrevistador: Valdir Pierote Silva. Deslocamentos e histórias de vida: trajetória da comunidade quilombola Riacho das Pedras atingida pela construção da Barragem Luiz Vieira em Rio de Contas-BA. 2009. 170 f. Relatório (Iniciação Científica) - Universidade de São Paulo, Rio de Contas, 2009.

MEIHY, J. C. S. B. Manual de história oral. São Paulo: Loyola, 2005.

MEIHY, J. C. S. B.; HOLANDA, F. História oral: como fazer, como pensar. São Paulo: Contexto, 2007.

MESQUITA, C. Morte e vida quilombola. Revista Palavra, Belo Horizonte, ano 2, n. 13, p. 58-62, 2000.

MESSEDER, M. L. L. Relatório de identificação da comunidade de Barra, Bananal e Riacho das Pedras - Estado da Bahia. Salvador: Fundação Palmares, 1998. Mimeo.

MESSEDER, M. L. L.; MARTINS, M. A. M. Arraiais de Rio de Contas: uma comunidade de cor. Caderno CRH, Salvador, v. 4, p. 36-49, 1991. Suplemento 1.

MIRANDA, J. C. Arraiais negros do Rio de Contas (Chapada Diamantina, Bahia). 1992. 67 f. Relatório Parcial (Bolsa de Aperfeiçoamento do CNPq) - Universidade Federal da Bahia, Salvador, 1992.

NOGUERA, R. Denegrindo a filosofia: o pensamento como coreografia de conceitos afroperspectivistas. Griot - Revista de Filosofia, Amargosa, v. 4, n. 2, p. 1-19, 2011.

NOGUERA, R. Denegrindo a educação: um ensaio filosófico para uma pedagogia da pluriversalidade. Revista Sul-Americana de Filosofia e Educação, Brasília, n. 18, p. 62-73, 2012.

PELLEJERO, E. A. A ideia de cultura na filosofia de Gilles Deleuze. Diacritica, Braga, v. 12, p. 241-252, 2008 .

PIEROTE-SILVA, J. P. Deslocamentos patrimoniais: polifonias, memórias e visualidades em Rio de Contas (BA). 2014. 111 f. Dissertação (Mestrado em Antropologia Social) - Universidade Federal de Goiás, Goiânia, 2014.

PIEROTE-SILVA, V. Deslocamentos e histórias de vida: trajetória da comunidade quilombola Riacho das Pe- dras atingida pela construção da Barragem Luiz Vieira em Rio de Contas-BA. 2009. 170 f. Relatório (Iniciação Científica) - Faculdade de Medicina, Universidade de São Paulo, São Paulo, 2009.

PIEROTE-SILVA, V.; BARROS, D. D. Método história oral de vida: contribuiçóes para a pesquisa qualitativa em terapia ocupacional. Revista de Terapia Ocupacional da Universidade de São Paulo, São Paulo, v. 21, n. 1, p. 68-73, 2010.

PINHEIRO, M. C. L.; COSTA, A. R. Inventário de referências culturais: apresentação. Salvador: MinC; IPHAN; TERRAGUÁ, 200-?. Mimeo.

ROCHA, R. A. Efeitos da Barragem Luiz Vieira sobre as comunidades de Barra, Bananal e Riacho das Pedras no município de Rio de Contas - BA. 2002. 134 f. Dissertação (Mestrado em Desenvolvimento Sustentável) - Universidade de Brasília, Brasília, 2002.

SAKAMOTO, L. O quilombo resiste. Revista Problemas Brasileiros, São Paulo, n. 342, p. 1-8, 2000. Disponível em: <http://www.reporterbrasil.com.br/reportagens/ quilombo/quilombo.pdf> Acesso em: 15 abr. 2015.

SANTOS, M. O espaço do cidadão. São Paulo: Nobel, 1993.

SANTOS, M. A falta de voz quilombola no canto brasileiro: as consequências da desvalorizaçáo da terra quilombola pelo estado brasileiro. Rio de Contas: SIT Graduate Institute/SIT Study Abroad, 2005. (Independent Study Project (ISP) Collection, Paper 467).

SILVA, M. A. L. A história de Maria Aparecida. [02 fev. 2009]. Entrevistador: Valdir Pierote Silva. Deslocamentos e histórias de vida: trajetória da comunidade quilombola Riacho das Pedras atingida pela construçáo da Barragem Luiz Vieira em Rio de Contas-BA. 2009. 170 f. Relatório (Iniciação Científica) - Universidade de São Paulo, Rio de Contas, 2009.

TARDE, G. Monadologia e sociologia e outros ensaios. São Paulo: Cosac \& Naify, 2007.

VASCONCELOS, A. L.; SOUZA FILHO, A. R. Bananal: trabalho e vivência em uma comunidade de negros. Politéia: História e Sociologia, Vitória da Conquista, v. 1, n. 1, p. 247-268, 2001.

WAGNER, R. A invenção da cultura. São Paulo: Cosac \& Naify, 2014.

\section{Fonte de Financiamento}

Fundação de Apoio à Pesquisa do Estado de São Paulo (FAPESP) e apoio do Núcleo Interdisciplinar de Memória e Imaginário (NIME-USP). A pesquisa foi orientada pela Profa. Dra. Denise Dias Barros do curso de Terapia Ocupacional da Faculdade de Medicina da Universidade de São Paulo (FM-USP). Em 2010, o trabalho recebeu da Fundação Cultural Palmares - Centro Nacional de Informação e Referência da Cultura Negra (CNIRC) o Prêmio Palmares de Monografia na categoria comunidades tradicionais. 


\section{Notas}

${ }^{1} \mathrm{Na}$ pesquisa, utilizamos a noção de trajetória apresentada por Bourdieu (2000, p. 189): “[...] série de posições sucessivamente ocupadas por um mesmo agente (ou um mesmo grupo) num espaço que é ele próprio um devir, estando sujeito a incessantes transformaçôes". Trata-se de proposição crítica em relação à ideia de história de vida como sequência linear de eventos no tempo e no espaço, sem contradiçôes, incompreensôes ou lacunas.

${ }^{2}$ Os interlocutores da nossa pesquisa tiveram importante participação na construção das suas narrativas: deram os títulos das histórias e colaboraram ativamente na edição dos dados textualizados. Optaram também por assinar as narrativas com seus nomes originais e, por isso, iremos referenciá-los nominalmente quando citados.

${ }^{3}$ Além de Riacho das Pedras, existem na cidade de Rio de Contas duas outras comunidades quilombolas chamadas Barra e Bananal. Ambas formavam junto com o vilarejo inundado uma espécie de unidade populacional, que embora distassem $1 \mathrm{~km}$ entre si, apresentavam história e representaçōes comuns.

${ }^{4}$ Em sua pesquisa, o antropólogo Messeder (1998) observou que parte dos escravizados que viveu em Rio de Contas pode ter vindo dessa região africana.

${ }^{5}$ Projeto do governo estadual que promovia eventos culturais no interior baiano.

${ }^{6}$ Termo inspirado na ideia de redevir indio de Danowski e Castro (2014).

${ }^{7}$ No sentido metafórico proposto por Oswald de Andrade em O Manifesto Antropofágico (ANDRADE, 2011).

${ }^{8}$ Palavra utilizada em seu sentido etimológico (escurecer, tornar negro). Refere-se também ao conceito criado pelo filósofo Renato Noguera, "[...] que significa enegrecer, assumir versões e perspectivas que não são hegemônicas, considerar a relevância das matrizes africanas para o pensamento filosófico, investigar em bases epistêmicas negro-africanas, dialogar, apresentar e comentar trabalhos filosóficos africanos, abordar filosoficamente temáticas como: relaçóes etnicorraciais, epistemicídio dos saberes de matriz negro-africana, racismo antinegro, branquitude e hegemonia dos parâmetros ocidentais no âmbito político e estético" (NOGUERA, 2011, p. 15-16). 